\title{
No, sin mi móvil. Diferencias de género y uso de las nuevas tecnologías
}

\author{
Not, without my phone. \\ Gender differences and use of new technologies
}

Carmen Sabater Fernández

Profesora del Departamento de Ciencias Humanas

(Universidad de La Rioja)

Josu Bingen Fernández Alcalde

Técnico de Empleo y Formación

(Servicio Vasco de Empleo)

Fecha de recepción: 5 de mayo de 2014

Fecha de revisión: 10 de enero de 2015

Para citar este artículo: Sabater Fernández, C. y Bingen Fernández Alcalde, J. (2015): Estereotipos de género y uso de las nuevas tecnologías, Icono 14, volumen (13), pp. 208-246. doi: 10.7195/ri14.v13i1.722 


\section{Resumen}

Los estereotipos de género han formado y siguen formando parte de la historia de la humanidad, marcando una diferencia de roles, ocupaciones, características físicas y rasgos de personalidad. La evolución social y económica ha influido notablemente en la disminución de las adscripciones por género pero persisten diferencias, más pronunciadas en las características de personalidad que repercuten en las conductas y hábitos cotidianos de ambos géneros. Este artículo analiza las diferencias por género en el uso de la tecnología, exponiendo las tendencias en la apropiación de los dispositivos tecnológicos en hombres y mujeres, desde la etapa de la adolescencia. Para este fin, se compararán los usos en informática y telefonía móvil por género, en base a la delimitación de rasgos expresivo-comunales en la mujer y rasgos agenteinstrumentales en los varones, a partir de una muestra de chicos y chicas de 14 a 20 años escolarizados/as en la Comunidad Autónoma de La Rioja.

Palabras clave: Estereotipos de género - Género - Nuevas Tecnologías - TIC

\section{Abstract}

Gender stereotypes have formed and continue to form part of the history of humanity, making a difference of roles, occupations, physical characteristics and personality traits. The social and economic development has greatly influenced the decline in gender ascriptions but differences more pronounced personality characteristics that influence the behavior and daily habits of both genders persist. This article examines gender differences in the use of technology and distance in the appropriation of technological devices in men and women from adolescence. To this end, uses computer and mobile phone are compared by gender, based on the definition of expressive-communal traits in women and agent-instrumental traits in males, from a sample of boys and girls from 14 to 20 years school / as in the Autonomous Community of La Rioja.

Key Words: Gender Stereotypes - Gender - New Technologies - ICT 
No, sin mi móvil. Diferencias de género y uso de las nuevas tecnologías $\mid 210$

\section{Introducción}

\subsection{Los estereotipos. Concepto y alcance}

El primer autor que utilizó el término estereotipo fue Walter Lippman (1922) que acuñó el concepto del símil de la estereotipia de las imprentas y de cómo la opinión pública se genera por un curioso procesamiento de repetición de las mismas imágenes en el pensamiento de las personas (Gaviria, López y Cuadrado, 2013: 417). De esta forma, a base de repetir cómo son las personas pertenecientes a determinados grupos, se conforma una imagen de sus miembros que va formando parte de la opinión pública.

En general, los estereotipos son creencias sobre las características que poseen un conjunto de personas derivadas de su pertenencia a un determinado grupo o categoría social. Henri Tajfel (1984) los define como imágenes muy simplificadas sobre personas o grupos que son compartidas, en sus características esenciales, por un gran número de personas (Gaviria, López y Cuadrado, 2013: 418). Para este autor, es fundamental considerar el consenso social y cultural existente sobre las características y atributos que constituyen un estereotipo, con la finalidad de poder comprender los procesos psicosociales que subyacen a su funcionamiento.

La organización de los estereotipos se basa en esquemas con creencias sobre diferentes aspectos como rasgos físicos, características de personalidad, roles y profesiones, o valores y preferencias. Todas las creencias y expectativas sobre estos atributos están relacionadas entre sí constituyendo teorías ingenuas que guían nuestras actitudes y conductas hacia ellos (Fiske, 2010. cit. en López y Cuadrado, 2013: 418). En este artículo, nos centraremos especialmente en los rasgos de personalidad ya que, tras una etapa de cambios sociales, políticos y económicos, es innegable que han variado las relaciones entre los grupos, pero todavía se mantienen rasgos permanentes en la categorización de género.

Las creencias contenidas en los estereotipos son consecuencia del proceso psicológico de la categorización social que permite clasificar a las personas en grupos en función de las características que tienen en común. Sin embargo, es-

DOI: ri14.v13i1.722 | ISSN: 1697-8293 | Año 2015 Volumen 13 Nº 1 | ICONO14 
tereotipar incorpora expectativas sobre cómo son o cómo se comportan los miembros de este grupo, y están mediados por el contexto social y por las relaciones intergrupales.

La formación de los estereotipos descansa en el proceso de categorización social y su transmisión se realiza básicamente a través de los agentes de socialización. Una vez establecidas las características que se atribuyen a un determinado grupo, el estereotipo guía la selección de la información congruente con su contenido por medio de una serie de procesos, tanto explícitos como implícitos, que contribuyen a su mantenimiento en el tiempo (Gaviria, López y Cuadrado, 2013: 424).

\subsection{El sistema sexo- género}

En 1949, en El segundo sexo, Simone de Beauvoir (1999) escribe la frase que inicia el movimiento feminista del siglo XX: "No se nace mujer, se llega a serlo". La visión de la femineidad como construcción social abre una reflexión que persiste en nuestros días.

A continuación, se presenta un resumen sobre las primeras investigaciones sobre el concepto de género que señalan que la marginación, subordinación, opresión, discriminación y exclusión de las mujeres no son naturales, sino elaboraciones histórico-culturales que expresan relaciones de poder basadas en las diferencias que distinguen a los sexos (Monzón, 2004: 8).

El concepto "género" fue introducido por la medicina y la psicología, para destacar un acontecimiento hasta entonces no valorado: la identidad y el comportamiento no estaban sólo determinados por el sexo biológico. El psicólogo y sexólogo neozelandés, John Money, introdujo el término en la literatura psicológica como "el rol de género" en 1955. Este autor (Money, 1988) busca enfrentar la dicotomía entre la naturaleza versus la cultura, entre lo innato versus lo adquirido, entre lo biológico versus lo social y entre lo psicológico versus lo fisiológico. De esta manera, Money buscaba demostrar que las niñas y los niños nacen psicosexualmente neutrales y se les puede asignar a uno u otro

ICONO14 | Año 2015 Volumen $13 N^{\circ} 1$ | ISSN: 1697-8293 | DOI: ri14.v13i1.722 
género durante los primeros años de su vida, con sólo un cambio en la práctica del aprendizaje, además de una sencilla intervención quirúrgica, dando la posibilidad de construir una nueva identidad de género, donde un niño podía convertirse en una niña, y una niña en un niño.

Por su parte, el psiquiatra y psicoanalista estadounidense, Robert Stoller (1964), partió de la perspectiva de identidad de género, analizando el caso de un paciente biológicamente hombre que fue amputado de sus genitales y criado como una mujer sin "mayores complicaciones". Stoller escribió Sex and gender en 1968 donde explicaba que existían áreas de la conducta humana como los pensamientos, los sentimientos y las fantasías, que se relacionan con el sexo biológico pero que, básicamente, eran construidas culturalmente. Stoller llegó a la conclusión de que género “...es un término que tiene connotaciones psicológicas y culturales más que biológicas; si los términos adecuados para el sexo son varón y hembra, los correspondientes al género son masculino y femenino, y estos últimos pueden ser bastante independientes del sexo biológico."(Stoller, R. 1968:187).

Los casos estudiados condujeron a Stoller a suponer que el peso y la influencia de las asignaciones socioculturales a los hombres y las mujeres, a través de factores como los ritos y las costumbres, y la experiencia personal, constituían los elementos que determinan la identidad y el comportamiento femenino o masculino y no el sexo biológico.

A partir de este descubrimiento acerca del papel de la socialización como elemento clave en la adquisición de la identidad femenina o masculina, Stoller y Money propusieron una distinción conceptual entre "sexo" y "género", en la cual el sexo se refiere a los rasgos fisiológicos y biológicos del ser macho o hembra, y el género, a la construcción social de esas diferencias sexuales.

En el ámbito de la antropología, Gayle Rubin, partiendo de los planteamientos de Marx, Lacan y Lévi -Strauss, define el sistema sexo/género como "el sistema de relaciones sociales que transforma la sexualidad biológica, que no debe confundirse con el sexo, en un producto de la actividad humana: en cuan- 
to a la división sexual del trabajo y la orientación heterosexual del erotismo" (Rubin, 1975).

Monique Wittig advierte que el sexo sólo es "una construcción mítica sofisticada, una formación imaginaria", que reinterpreta las características físicas (que en sí mismas son neutras) mediante la red de relaciones en que son percibidas" (Wittig, 1992: 11-12).

También en los años 90, Judith Butler pone en acción este binarismo:

El género es una construcción cultural; por consiguiente no es ni resultado causal del sexo ni tan aparentemente fijo como el sexo... Al teorizar que el género es una construcción radicalmente independiente del sexo, el género mismo viene a ser un artificio libre de ataduras; en consecuencia, hombre y masculino podrían significar tanto un cuerpo femenino como uno masculino; mujer y femenino, tanto un cuerpo masculino como un femenino (Butler, 2001: 6).

El género es un acto de sujeción y el precio de la subversión es la pérdida de reconocimiento, e incluso, el riesgo físico.

El carácter relacional de la categoría 'género' permite vincular las esferas pública y privada, explicar la persistente desigualdad social y la inequitativa distribución de poder y autoridad entre hombres y mujeres; asimismo, dada su calidad integradora y multidisciplinaria, posibilita conocer con amplitud y profundidad la realidad social.

El uso de esta categoría, además, ha establecido que cada sociedad desarrolla órdenes de género específicos y que "las sociedades hegemónicas imponen sus modelos a otras, a través de procesos de conquista, colonización e imperialización".

Al conjugar el género con las categorías de clase, etnia y raza, se evidencia la relación dialéctica entre estas condiciones sociales y cómo todas se modifican entre sí, constituyéndose en una constante que atraviesa los ejes económico, étnico, político, simbólico y cultural. De aquí que, parafraseando a Marcela Lagarde, es diferente la pertenencia a una clase o etnia si se es hombre o mujer, y es diferente ser mujer o ser hombre de acuerdo con la clase, la raza o la etnia.

ICONO14 | Año 2015 Volumen 13 № 1 | ISSN: 1697-8293 | DOI: ri14.v13i1.722 
No, sin mi móvil. Diferencias de género y uso de las nuevas tecnologías $\mid 214$

A continuación, se presentan algunos elementos teóricos de las principales categorías que orientan la reflexión y análisis en torno a la dimensión de género.

\section{Discusión}

\subsection{El género como categoría de análisis}

El género es una categoría de análisis que está "intrínsecamente vinculada a la práctica y construcción teórica del feminismo" y que se ha constituido en una herramienta para la 'reinterpretación de los procesos histórico sociales' (Monzón, 2004: 20).

Hay diferentes vertientes científicas que han contribuido a la conceptualización del género: la médico/psicológica, la antropológica, la histórica y la sociológica.

1. La médico/psicológica centrada en el sexo, en tanto que los rasgos biológicos tienen una importancia crucial en la explicación acerca de las diferencias sexuales y conductuales de los seres humanos. El sexo es el conjunto de características genotípicas y fenotípicas presentes en los sistemas, funciones y procesos de los cuerpos humanos.

Las siguientes vertientes se centran en el género como una construcción imaginaria y simbólica que contiene el conjunto de atributos asignados a las personas a partir de la interpretación valorativa de su sexo.

2. La antropológica desde el eje sexo-género: con el interés por averiguar 'cómo la cultura expresa las diferencias entre hombres y mujeres' y porqué estas diferencias han sido un factor determinante para justificar la desigualdad entre los géneros.

En esta vertiente, desde la que se han realizado importantes contribuciones teóricas desde el feminismo, se representa la sociedad culturalmente androcéntrica que sintetiza el pensamiento dominante. 


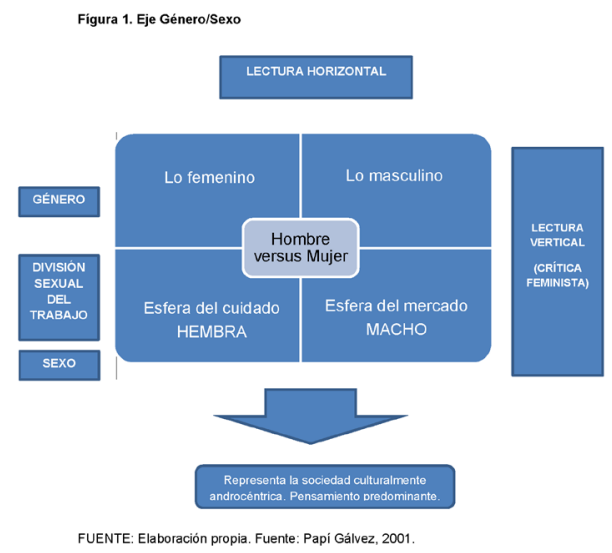

Figura1

3. La sociológica, desde el género como categoría dentro de la estructura social. Desde esta perspectiva, se analizarían conceptos tales como división sexual del trabajo, jerarquía, desigualdad estructurada, patriarcado... y su relación con otras categorías como la etnia y la clase.

4. La histórica, con el estudio de la dinámica y el cambio histórico-social.

El género es una categoría en la que se articulan tres instancias básicas:

a) La atribución y asignación del género en el momento del nacimiento, a partir de la apariencia externa de los genitales;

b) La identidad de género que supone el conocimiento de la existencia de una división de la sociedad, en los hombres y las mujeres;

c) El rol de género, que es el conjunto de normas y prescripciones que cada sociedad establece sobre lo que es "femenino" y "masculino".

Desde la antropología y la sociología, el concepto de género contribuye a replantear la forma de entender cuestiones fundamentales de la organización social, económica y política. 
Estas categorías sociales varían de un lugar a otro, dependiendo de la etnia y el período histórico, atribuyendo rasgos de lo que se considera masculino y femenino, y definiendo así la manera de comportarse y reconocerse como mujer o como hombre.

A partir de la asignación social de roles a cuerpos sexuados, se construye la autoidentidad delimitando lo que es el "deber ser" para las mujeres y el "deber ser" para los hombres. Este "deber ser" constituye la dimensión prescriptiva de los estereotipos, con elementos impuestos por el entorno social. Debido a los roles genéricos impuestos, las mujeres generalmente definen lo que son y hacen en relación con lo reproductivo, por ejemplo: "ser amas de casa", "cocinar, "ser madres"; mientras los hombres se definen por lo productivo.

La identidad de género se refiere principalmente a aquellas características sociales y culturales que cada sociedad asigna al comportamiento de mujeres y hombres, a partir de sus diferencias sexuales. Ubica a cada persona en roles sexuados, condicionados por factores biológicos, psicológicos y sociales, que van a conformar una parte importante de su personalidad y van a determinar sus relaciones con los demás. De este modo, podemos hablar, por un lado, de la percepción de nuestra identidad de género, es decir, de aspectos psicológicos, y por otro, de cómo nos mostramos hacia los demás, relacionado con aspectos sociológicos. La identidad de género estudia las creencias de roles y responsabilidades apropiados para hombres y mujeres, y la relación que se establece entre ellos (Moya y De Lemus, 2004).

En el marco de esta nueva concepción, Sandra Bem (1974) crea el instrumento de medida de identidad de género más utilizado en la investigación: el Bem Sex Role Inventory (BSRI). El objetivo de este inventario es comprobar hasta qué punto las personas, independientemente de su sexo biológico, se identifican con características de personalidad típicamente femeninas o típicamente masculinas (Gaviria y López, 2013: 23).

Recapitulando, mientras el término "sexo" hace referencia a la clasificación de las personas a partir de categorías sociodemográficas de hombres y mujeres; la

DOI: ri14.v13i1.722 | ISSN: 1697-8293 | Año 2015 Volumen 13 Nº 1 | ICONO14 
categoría "género" se refiere a los juicios o inferencias sobre los sexos, a las características psicosociales a ellos asociados. Kay Deaux (1985, 1999 cit. en Gaviria y López, 2013: 21), psicóloga experta en estudios de género, recomienda utilizar el término "sexo" cuando se hace referencia a diferencias en una categoría demográfica (hombre o mujer) y el término "género" cuando se aplica a aspectos culturales de esas diferencias. El sexo se basa en la biología, mientras que el género hace referencia a aspectos psicológicos y sociales: se refiere a qué se considera masculino o femenino en una sociedad y a cómo el individuo se ve a sí mismo en términos de feminidad o masculinidad dentro de su cultura.

\subsection{Los estereotipos de género}

En el estudio de la distinción entre los mecanismos biológicos y los aspectos sociales de la masculinidad y la feminidad, la década del 70 del siglo pasado resultó relevante al producirse un giro en el debate, pues ya no se trataba de analizar la existencia de diferencias entre hombres y mujeres, sino de estudiar lo que las personas piensan acerca de los hombres y las mujeres. La discusión ya no se focalizó en cómo son los hombres y las mujeres, sino en cómo se tiende a percibirlos (Cuadrado, 2007).

Deaux y Lewis (1984) investigaron los componentes de los estereotipos de género que las personas utilizaban para diferenciar a los hombres de las mujeres, comprobando que éstos están referidos a rasgos, roles ocupaciones y características físicas. En este estudio, nos basamos fundamentalmente en la estereotipia de rasgos de personalidad que hace referencia a las características que se considera que definen de forma diferente a hombres y mujeres (la mujer es más emocional, sensible, más preocupada por los otros; y el hombre, más agresivo, independiente y competitivo).

En las investigaciones sobre el género, lo relacionado con la dimensión femenina recibe el nombre de "expresivo comunal" y lo relacionado con la dimensión masculina se denomina "instrumental o agente" (Bakan, 1966 basada en la distinción de Parsons y Bales, 1955).

ICONO14 | Año 2015 Volumen 13 Nº 1 | ISSN: 1697-8293 | DOI: ri14.v13i1.722 


\begin{tabular}{|c|c|}
\hline $\begin{array}{l}\text { Orientación del rol instrumental } \\
\text { Competencia }\end{array}$ & $\begin{array}{l}\text { Orientación expresiva comunal } \\
\text { Cordialidad }\end{array}$ \\
\hline 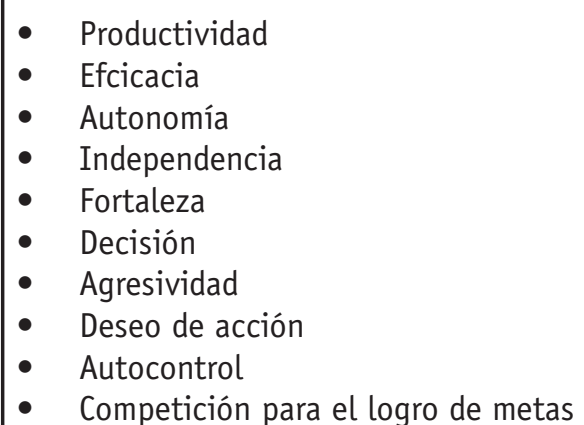 & $\begin{array}{l}\text { - } \text { Afectividad } \\
\text { - } \text { Compasión } \\
\text { - } \text { Preocupación por los demás } \\
\text { - } \text { Dependencia } \\
\text { - }\end{array}$ \\
\hline
\end{tabular}

Tabla 1: Eje Género/Sexo. Fuente: Martínez y Paterna, 2001.

\subsection{Estereotipos de género y conductas tecnológicas}

En este sentido, siguiendo a Martínez, Aguado y Tortajada (2009: 15- 16), los primeros estudios apuntaban a que el uso del móvil por parte de los hombres estaba mayoritariamente relacionado con el trabajo y con el ocio tecnológico, mientras que, en el caso de las mujeres, estaría más vinculado a la identidad y a las relaciones interpersonales. Estudios posteriores en Australia, Gran Bretaña o en Israel señalan diferencias en el acceso a las innovaciones tecnológicas y en el consumo de contenidos vía móvil. En línea similar, se plantean prospecciones cuantitativas de mercado. En general, los datos de la literatura cuantitativa abundan en referencias a la mayor resistencia femenina a la adopción de innovaciones tecnológicas frente a su mayor integración, una vez adoptadas, en el espacio simbólico de la vida cotidiana y las relaciones interpersonales.

Estos autores utilizando teorías como las de Lemish y Cohen (2005) que abordan el estudio de la tecnología móvil en perspectiva de género, tienen en cuenta la correlación de tres dimensiones: la dimensión de género de la tecnología, la dimensión de género de la integración simbólica y funcional de la tecnología por los/as 
usuarios/as en su vida cotidiana y, finalmente, las cifras que reflejan los hábitos de uso y el acceso a las tecnologías. Añaden otras perspectivas de interés como la de Wajcman (1991: 190), por la que las tecnologías como productos socioculturales, encierran formas de conocimiento y capacidades asociadas al género (el «género de la tecnología») y la de Turkle (1995) que señala las denominadas «tecnologías de relación» como articulaciones femeninas de la tecnología (según esta perspectiva, Internet o el móvil serían, pues, tecnologías femeninas).

Martínez, Aguado y Tortajada (2009) defienden el enfoque de la apropiación, entendida como el proceso de integración simbólica y funcional de la tecnología en la vida cotidiana y las transformaciones en la significación de la tecnología en la vida social, derivadas de la misma. Los ejes semánticos que recogen este enfoque comprenden:

1. La gestión de la identidad: Se relaciona con la identidad individual y colectiva como resultado y territorio de constantes negociaciones que tienen lugar en las interacciones cotidianas (Goffman, 1963). Se extienden en la gestión de los roles sociales (público- privado), la toma de decisiones respecto a la planificación, la presentación de la persona en sociedad, y la utilidad del móvil como herramienta de socialización.

2. La conciliación de la vida familiar/ afectiva y laboral: relacionado con la disolución de las fronteras sociales en los espacios/ interacciones privadas versus públicas, y entre los ámbitos de la vida cotidiana.

3. La seguridad fisica y emocional: los autores siguen a Giddens (1995: 113 cit. por Martínez, Aguado y Tortajada, 2009: 20) en la definición de la seguridad ontológica con una doble dimensión física (como respuesta a emergencias y amenazas) y emocional (mejora de la estabilidad y reducción del aislamiento).

Este enfoque se asimila con el proceso de remediación descrito por Islas- Carmona (2008: 31) según el cual se produce un proceso por el que los medios de comunicación se presentan como el resultado de una adecuación dialéctica que 
permite transformarlos hasta convertirlos en lógicas extensiones de nuestras facultades, órganos o sentidos. Sin embargo, se distancia de los primeros autores en el determinismo básicamente femenino o masculino de los dispositivos tecnológicos ya que estas representaciones significarían un proceso de adecuación entre dispositivos, aplicaciones y funcionalidades adaptadas a cada género. En cualquier caso, la apropiación es simbólica y está intrínsecamente vinculada con el individuo y su vida cotidiana, no sólo con el género.

Nuestra propuesta es analizar las tendencias que distancian a ambos géneros del uso de las TIC en su uso relacional en el caso de las mujeres y en su uso instrumental en el caso de los varones. En la actualidad, si bien es cierto que existen preferencias y diferencias entre los géneros, las aplicaciones comprenden múltiples posibilidades que amplían una diferenciación dicotómica de la misma, y que implicaría incluir otras dimensiones transversales de etnia, clase social, profesión, etc.

\subsection{Objetivo e hipótesis}

El objetivo general del estudio es analizar la correspondencia entre los estereotipos de género, en particular, los componentes de rasgos denominados "expresivo comunales" en lo femenino y "agente instrumentales" en lo masculino. Se pretende establecer si, pese a los cambios sociales relacionados con los roles de género y la disminución de la estereotipos de género, todavía se produce diferencias derivadas, tanto del proceso de socialización, como de los roles socio-económicos.

Precisamente, las teorías ya nombradas sirven como punto de partida para relacionar las TIC con la afectividad y la necesidad de relacionarse de las mujeres mientras que, en los varones, se relacionarían más con el entretenimiento, la información y la acción.

La hipótesis central del estudio deriva de que, todavía, existen significativas distancias en la vida cotidiana de varones y mujeres que inciden en aspectos tan básicos como la diferencia en el uso de la informática. No se plantea si estas diferencias proceden de un origen biológico, de la influencia de los agentes

DOI: ri14.v13i1.722 | ISSN: 1697-8293 | Año 2015 Volumen 13 N 1 | ICONO14 
socializadores o de los roles socio-culturales, asumiendo que se trata de una influencia recíproca entre estos factores. Su contenido se orienta a la diferencia del uso de la tecnología en uno u otro género: el varón se manifiesta más proclive a su uso y más abierto a las novedades mientras que la mujer es más reacia a los cambios pero, cuando las adopta, realiza un uso más intensivo centrado predominantemente a lo relacional, orientado a la relación con su círculo familiar y de amigos/as.

\subsection{Metodología}

La metodología utilizada se ha basado en la triangulación intermétodos, que combina:

1. Metodología cualitativa con datos obtenidos mediante la técnica de entrevista semiestructurada y análisis documental de fuentes secundarias.

Las entrevistas semiestructuradas fueron realizadas por 12 alumnos seleccionados de forma aleatoria, entre jóvenes y adolescentes de 14 a 18 años. La finalidad era analizar los hábitos de uso de las TIC y la percepción de la privacidad en Internet.

2. Metodología cuantitativa de fuentes primarias, con datos obtenidos mediante la técnica de encuesta estandarizada.

La población de este estudio estaba compuesta por 11.891 estudiantes que estuvieron matriculados en $3^{\circ}$ y $4^{\circ}$ de Educación Secundaria Obligatoria (ESO), en $1^{\circ}$ y $2^{\circ}$ curso de Bachillerato, Ciclos de Grado Medio y Programas de Cualificación y Perfeccionamiento para el Empleo (PCPI) de todos los centros públicos y privados de la Comunidad Autónoma de La Rioja, durante el Curso 2011/12.

Los datos recogidos para este artículo proceden básicamente de la fase cuantitativa, basada en un cuestionario, que comprende variables dependientes de hábitos de uso y del nivel de privacidad en Internet y telefonía móvil; y variables

ICONO14 | Año 2015 Volumen $13 N^{\circ} 1$ | ISSN: 1697-8293 | DOI: ri14.v13i1.722 
independientes de datos socio-demográficos. En este estudio, se analizarán las diferencias de las conductas tecnológicas por género pero esta interpretación se completara con variables transversales de edad, etnia y uso de las redes sociales.

La muestra cuantitativa comprende 400 jóvenes de 14 a 20 años, escolarizados en la Comunidad Autónoma de La Rioja. El tipo de muestra seleccionado se basó en la máxima aleatoriedad para garantizar la fiabilidad y la validez de los resultados. Para ello, se seleccionó un muestreo polietápico por cuotas de zonas de La Rioja, tipo de centro (privado, público) y curso escolar.

Para elaborar el cuestionario, se tomó como referencia los estados de privacidad de Westin $(1967,2004 a, 2004 b)$ y definiciones de autores como Shils (1966) y Goffman (1963). Un vez definidos los objetivos generales de la investigación, se realizó la adaptación al uso de los medios tecnológicos, se rediseñó y se elaboró uno ad hoc para la misma.

Posteriormente, el cuestionario se sometió a un pre-test con el fin de asegurar que los ítems cumplían los requisitos establecidos y previstos para los objetivos de la investigación. Para ello, se contactó con 15 estudiantes pertenecientes a la población objeto de estudio, solicitándoles que se pronunciasen sobre:

a) posibles errores de comprensión en la formulación de las preguntas,

b) claridad en la formulación del lenguaje empleado,

c) exposición y orden de la información presentada y

d) amplitud de contenidos de los ítems formulados.

Tras su recogida, se procedió a modificar el cuestionario inicial, obteniendo un instrumento constituido por 49 preguntas, basadas en las dimensiones nucleares de lo íntimo-lo privado-lo público, basadas en los estados de Westin (1967, 2004a, 2004b) y en las fuentes teóricas utilizadas. 
En concreto, las variables se basaron en los siguientes indicadores:

- Privacidad como nivel de reserva de información y de relaciones sociales.

- Publicidad de los datos en Internet, mediante los mensajes privados y la publicación de la información en el muro/tablón de las redes sociales.

- Uso de Internet y de sus aplicaciones, nivel de uso, y percepción de la seguridad y del control.

- Datos independientes sobre género, edad, tipo de centro, nivel socioeconómico, y residencia.

Los datos resultantes se procesaron a través del programa de estadística SPSS, 19.0 de Windows. Para el presente estudio, se han utilizado pruebas de correlación Chi-Cuadrado y Phi de Kramer para variables nominales y ordinales. A partir de la existencia de asociación entre las variables, se ha aplicado el método ANOVA para verificar si existe diferencia de medias en hábitos de uso de las tecnologías (Internet, redes sociales y teléfono móvil), por variables socio-demográficas ${ }^{1}$.

\section{Resultados}

\subsection{Metodología cualitativa}

Los resultados generales de las entrevistas semiestructuradas comprendían usos diferenciados en las redes sociales entre hombres y mujeres. De esta forma, las mujeres se dedicaban más a exponer sus fotografías y sus vídeos, a hablar con otros amigos/as, a utilizar las aplicaciones sociales de la red social como los mensajes 0 del móvil, como el Whatsapp y a compartir información sobre música y cine. Los hombres denotaban una mayor inclinación por los deportes, fundamentalmente, por los campeonatos de fútbol, por los juegos de contenido más violento, por medios de comunicación como la TV y la radio, y por la participación activa en foros de TIC y de juegos informáticos.

ICONO14 | Año 2015 Volumen $13 N^{\circ} 1$ | ISSN: 1697-8293 | DOI: ri14.v13i1.722 
Sin embargo, era necesario contrastar estas diferencias para conocer si realmente existían diferencias válidas por género que, además, coincidirían con los estereotipos por rasgos de conducta. Con esta finalidad, se analizan a continuación las principales diferencias localizadas en el estudio cuantitativo, basado en la metodología de encuesta.

\section{La presencia de las mujeres en Internet}

Si tenemos en cuenta los datos de los menores de 18 años de edad en España, siguiendo datos del INE (2013), las mujeres superan a los varones en el uso del ordenador y en el uso de Internet. De esta forma, un $96,2 \%$ de mujeres menores utiliza el ordenador frente al $94,1 \%$ de varones. En la misma línea, su uso de Internet alcanza un 92,9\% frente al 90,7 \% de los hombres. Si bien, las diferencias no son demasiado elevadas; el dato más significativo es el importante aumento del uso femenino que ha llegado a superar al masculino.

En relación a la frecuencia de uso de Internet, en nuestra población no existen diferencias por género, si bien las chicas mayores de edad son el segmento con menor uso durante la semana (45\% de varones mayores de 17 años utilizan Internet más de dos horas frente al 15\% de mujeres). En cualquier caso, tanto el uso de las chicas como el de los chicos se sitúa en una media de 1-2 horas diarias.

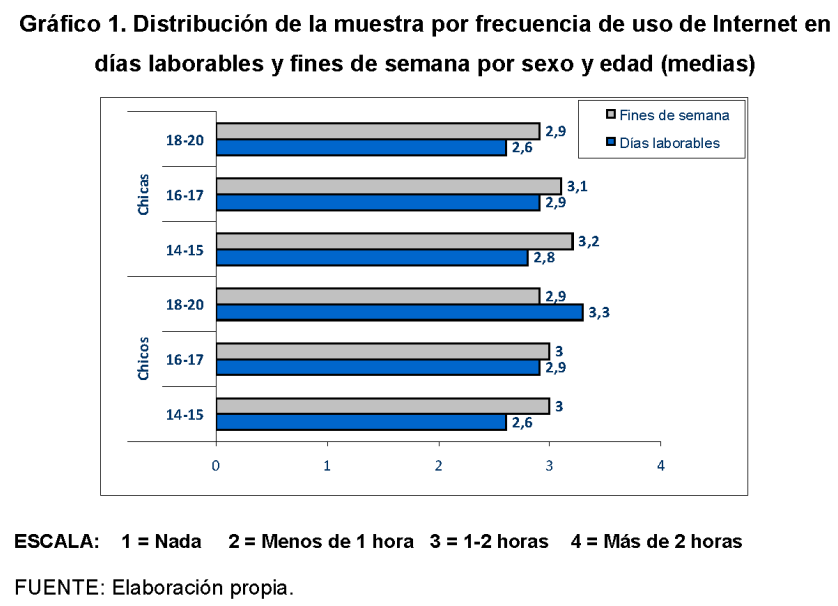

Figura 2

DOI: ri14.v13i1.722 | ISSN: 1697-8293 | Año 2015 Volumen 13 Nº 1 | ICONO14 
Si atendemos al dato del aprendizaje de las TIC, los mayores de edad (18-20 años) han aprendido, en mayor medida, solos y/o con la ayuda de agentes socializadores formales (profesores, padres). En los menores de edad, destaca la presencia de otros "nativos digitales" (familiares y amigos/as de su edad) y de expertos. Respecto al sexo, el proceso de aprendizaje se presenta más autónomo en los chicos ya que las chicas declaran haber recibido más apoyo de todos los agentes, formales e informales.

\begin{tabular}{|c|c|c|c|c|c|c|c|}
\hline \multirow{2}{*}{ Respuestas } & \multicolumn{2}{|c|}{$14-15$ años } & \multicolumn{2}{c|}{$16-17$ años } & \multicolumn{2}{c|}{18 -20 años } & \multirow{2}{*}{ TOTAL } \\
\cline { 2 - 7 } & Chicos & Chicas & Chicos & Chicas & Chicos & Chicas & \\
\cline { 2 - 8 } Solo & 54,2 & 50,8 & 52,7 & 50,5 & 66,7 & 48,5 & \multirow{2}{*}{53,1} \\
\hline Hermano & 13,6 & 15,9 & 10,8 & 13,1 & 4,8 & 12,1 & 12,1 \\
\hline Experto & 13,6 & 12,7 & 8,6 & 12,1 & 7,1 & 9,1 & 10,8 \\
\hline Padre/madre & 8,5 & 6,3 & 6,5 & 3,7 & - & 15,2 & 6,0 \\
\hline $\begin{array}{c}\text { Amigo/familiar/ } \\
\text { adulto }\end{array}$ & 3,4 & 4,8 & 12,9 & 2,8 & 14,3 & 3,0 & 6,8 \\
\hline Novio/a & 3,4 & 4,8 & 7,5 & 8,4 & 2,4 & 3,0 & 5,8 \\
\hline Profesor & 1,7 & 4,8 & 1,1 & 7,5 & 4,8 & 9,1 & 4,5 \\
\hline Amigo de tu edad & 1,7 & - & - & 1,9 & - & - & 0,8 \\
\hline TOTAL & 100 & 100 & 100 & 100 & 100 & 100 & 100 \\
\hline
\end{tabular}

Tabla 2: Quién te ha enseñado internet, por sexo y edad (\%). Fuente: elaboración propia.

Respecto al conocimiento declarado de Internet, las chicas se posicionan más en categorías intermedias, en particular en el nivel medio avanzado, mientras que los chicos y los jóvenes mayores de edad duplican a sus homónimas femeninas en su clasificación como expertos.

\begin{tabular}{|c|c|c|c|c|c|c|c|}
\hline \multirow{2}{*}{ Respuestas } & \multicolumn{2}{|c|}{$14-15$ años } & \multicolumn{2}{c|}{$16-17$ años } & \multicolumn{2}{|c|}{$18-20$ años } & \multirow{2}{*}{ TOTAL } \\
& & & & & \\
& Chicos & Chicas & Chicos & Chicas & Chicos & Chicas & \\
\hline Principiante & 3,4 & 7,9 & 5,4 & 5,6 & 7,1 & 6,3 & 5,8 \\
\hline
\end{tabular}




\begin{tabular}{|c|c|c|c|c|c|c|c|}
\hline \multirow{2}{*}{ Respuestas } & \multicolumn{2}{|c|}{$14-15$ años } & \multicolumn{2}{|c|}{$16-17$ años } & \multicolumn{2}{c|}{$18-20$ años } & \multirow{2}{*}{ TOTAL } \\
\cline { 2 - 7 } & Chicos & Chicas & Chicos & Chicas & Chicos & Chicas & \\
\hline $\begin{array}{c}\text { Nivel medio- } \\
\text { avanzado }\end{array}$ & 86,4 & 85,7 & 84,9 & 89,7 & 73,8 & 87,5 & 85,6 \\
\hline Experto & 10,2 & 6,3 & 9,7 & 4,7 & 19,0 & 6,3 & 8,6 \\
\hline TOTAL & 100 & 100 & 100 & 100 & 100 & 100 & 100 \\
\hline
\end{tabular}

Tabla 3: Nivel declarado de uso de internet por sexo y edad (\%). Fuente: elaboración propia.

Las mujeres mantienen un comportamiento de uso más privado, con mayor uso solas en su habitación, y menor uso en lugares públicos.

\begin{tabular}{|c|c|c|c|c|c|c|c|}
\hline \multirow{2}{*}{ Respuestas } & \multicolumn{2}{|c|}{ 14-15 años } & \multicolumn{2}{|c|}{ 16-17 años } & \multicolumn{2}{|c|}{$18-20$ años } & \multirow{2}{*}{ TOTAL } \\
\hline & Chicos & Chicas & Chicos & Chicas & Chicos & Chicas & \\
\hline $\begin{array}{c}\text { En mi habitación } \\
\text { solo/a }\end{array}$ & 46,6 & 50,8 & 47,3 & 47,7 & 47,6 & 51,5 & 48,2 \\
\hline $\begin{array}{l}\text { En otro lugar de la } \\
\text { casa }\end{array}$ & 29,3 & 39,7 & 25,8 & 29,9 & 14,3 & 24,2 & 28,3 \\
\hline En cualquier sitio & 8,6 & 6,3 & 9,7 & 7,5 & 9,5 & 12,1 & 8,6 \\
\hline $\begin{array}{l}\text { En mi habitación } \\
\text { compartida }\end{array}$ & 10,3 & 3,2 & 12,9 & 7,5 & 4,8 & 9,1 & 8,3 \\
\hline En el colegio & 3,4 & - & - & 0,9 & 19,0 & - & 2,8 \\
\hline $\begin{array}{l}\text { En un lugar público } \\
\text { (bibliotecas, ludo- } \\
\text { tecas) }\end{array}$ & 1,7 & - & 3,2 & - & 4,8 & 3,0 & 1,8 \\
\hline $\begin{array}{c}\text { En casa de un } \\
\text { amigo }\end{array}$ & - & - & - & 4,7 & - & - & 1,3 \\
\hline $\begin{array}{l}\text { En casa de un } \\
\text { familiar }\end{array}$ & - & - & 1,1 & 1,9 & - & - & 0,8 \\
\hline TOTAL & 100 & 100 & 100 & 100 & 100 & 100 & 100 \\
\hline
\end{tabular}

Tabla 4: Principal lugar de uso de internet por sexo y edad (\%). Fuente: elaboración propia. 
En relación a otros estudios (Bringué y Sádaba, 2011: 213), los datos no siguen la misma línea de resultados ya que, en este estudio, las chicas son más conscientes de los riesgos de Internet -mientras que, en la población española, son los chicos- y llegan a superar esta percepción de la conciencia del riesgo en más del 10 $\%: 91,6 \%$ declara ser consciente de los riesgos de Internet frente al 81,4 \% de los varones. Y, en la misma medida, declaran controlar mejor los riesgos: un 84,2 \% de mujeres considera que los controla frente al 73,3\% de varones.

\subsection{Las mujeres y el uso de las aplicaciones de Internet}

Por género, el uso de las redes sociales es superior en las chicas, sobre todo en el segmento de menor edad (14-15 años) que, también, aparece con mayor presencia en otras aplicaciones sociales, como el Chat, el correo electrónico, el Fotolog y el Skype. Los chicos navegan más por las páginas de Internet, descargan más programas y usan más la radio y la televisión. La división de géneros delimita una línea entre lo expresivo-comunal, un mundo más social, afectivo y comunicativo para ellas, y lo agente-instrumental, un mundo de acción, más audiovisual, utilitario y competitivo para ellos. De hecho, la tendencia es el mayor uso de funcionalidades basadas en el elemento afectivo/ relacional en las chicas y de funcionalidades basadas en la acción, el entretenimiento, el mundo audiovisual y la especialización en las TIC en los chicos.

\begin{tabular}{|c|c|c|c|c|c|c|c|}
\hline \multirow{2}{*}{ Respuestas } & \multicolumn{2}{|c|}{$14-15$ años } & \multicolumn{2}{c|}{$16-17$ años } & \multicolumn{2}{c|}{$18-20$ años } & \multirow{2}{*}{ TOTAL } \\
\cline { 2 - 7 } & Chicos & Chicas & Chicos & Chicas & Chicos & Chicas & \\
\hline Redes sociales & 57,6 & 55,6 & 45,2 & 57,0 & 39,0 & 48,5 & 51,5 \\
\hline Visitar webs & 15,3 & 15,9 & 29,0 & 10,3 & 26,8 & 15,2 & 18,4 \\
\hline $\begin{array}{c}\text { Descargar } \\
\text { programas }\end{array}$ & 16,9 & 6,3 & 16,1 & 7,5 & 17,1 & 9,1 & 11,9 \\
\hline Chatear Messenger & 5,1 & 11,1 & 6,5 & 9,3 & - & 21,2 & 8,3 \\
\hline Correo electrónico & 17,5 & 3,2 & 1,1 & 9,3 & 7,3 & 3,0 & 4,5 \\
\hline TV/radio & - & - & 2,2 & 0,9 & 4,9 & 3,0 & 1,5 \\
\hline Fotolog & 1,7 & 4,8 & - & 0,9 & - & - & 1,3 \\
\hline
\end{tabular}

ICONO14 | Año 2015 Volumen 13 Nº 1 | ISSN: 1697-8293 | DOI: ri14.v13i1.722 


\begin{tabular}{|c|c|c|c|c|c|c|c|}
\hline \multirow{2}{*}{ Respuestas } & \multicolumn{2}{|c|}{$14-15$ años } & \multicolumn{2}{c|}{$16-17$ años } & \multicolumn{2}{c|}{$18-20$ años } & \multirow{2}{*}{ TOTAL } \\
\cline { 2 - 8 } & Chicos & Chicas & Chicos & Chicas & Chicos & Chicas & \\
\hline $\begin{array}{c}\text { Foros, listas de } \\
\text { correo }\end{array}$ & 1,7 & - & - & 1,9 & 2,4 & - & \multirow{2}{*}{1,0} \\
\hline Blog personal & 2,4 & - & - & 1,9 & 2,4 & - & 1,0 \\
\hline Teléfono Skype & - & 1,6 & - & 0,9 & - & - & 0,5 \\
\hline TOTAL & 100 & 100 & 100 & 100 & 100 & 100 & 100 \\
\hline
\end{tabular}

Tabla 5: Primera aplicación más utilizada en internet por sexo y edad (\%). Fuente: elaboración propia.

El Chat fue una de las primeras aplicaciones de Internet y su uso persiste entre los jóvenes en sus diferentes modalidades, como una de las principales actividades interactivas (Whatsapp, Skype, Chat de las redes sociales, mensajería instantánea). De hecho, chatear se presenta como una actividad frecuente en los jóvenes. Casi la mitad $(45,4 \%)$ declara chatear con frecuencia sobre temas de opinión. Esta actividad se realiza más por los chicos, que superan ampliamente a las chicas: así, un 50,3\% de varones reconoce hacerlo con frecuencia frente al 40,7\% de mujeres. Son jóvenes que chatean sobre aficiones en grupos de afinidad pero que manifiestan mayor cautela a la hora de hablar de asuntos personales.

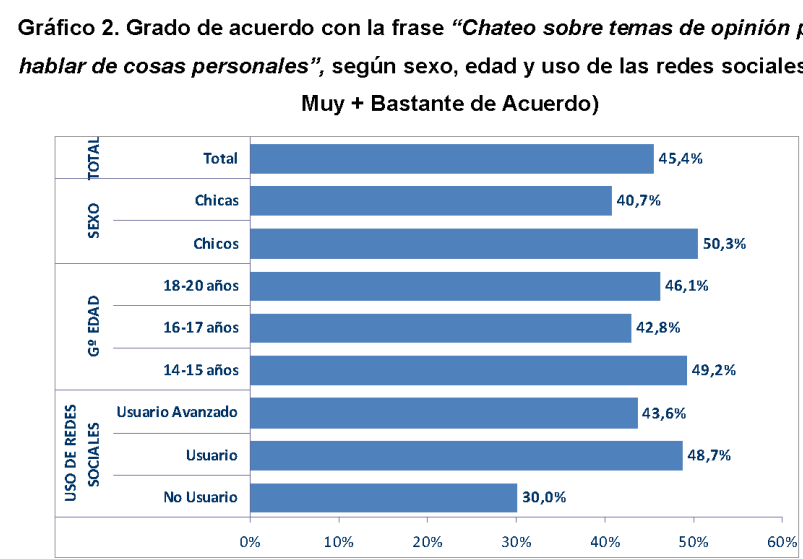

FUENTE: Elaboración propia

Figura 3

DOI: ri14.v13i1.722 | ISSN: 1697-8293 | Año 2015 Volumen 13 N 1 | ICONO14 
Este "yo narrador" se despliega en Internet desde una identidad real que no engaña sino que extiende una parte de su vida sin la ficción de camuflajes, como el nick, o el refugio de un personaje. Así, la tercera parte de los jóvenes $(30,7 \%)$ se identifica sobre cosas personales, sin engañar. Entre este segmento, destacan las chicas, sobre todo, las de origen extranjero y las que presentan un alto uso de las redes sociales. Esta realidad no es generalizable a toda población juvenil femenina sino que se extiende a una tercera parte de las mujeres (34,5\%), un segmento con una alta confianza que ofrece sus detalles personales por Internet.

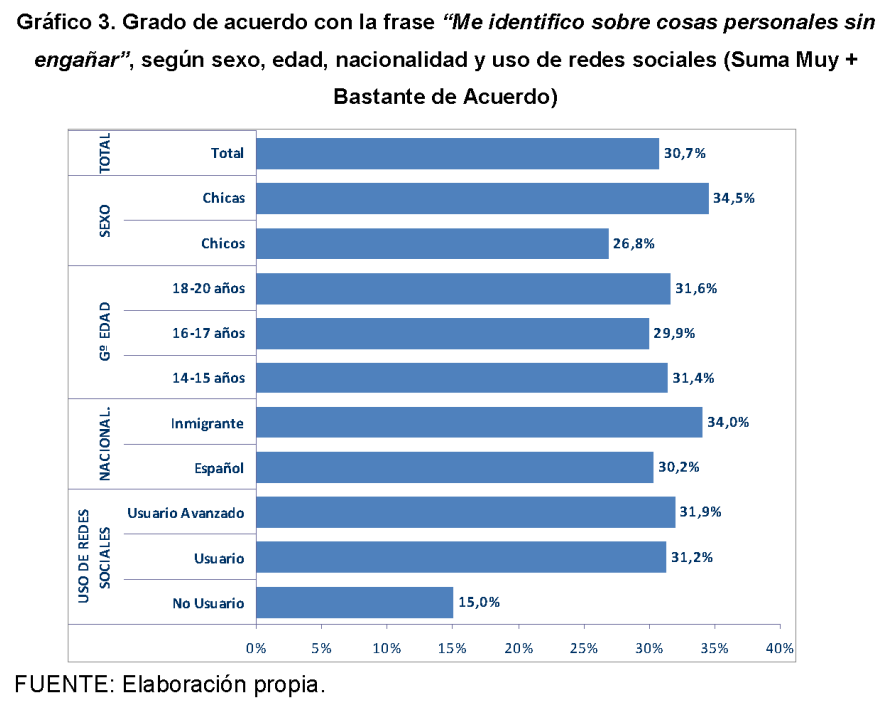

Figura 4

La segmentación y diversificación del público juvenil se extiende en otro tipo de exteriorización, como es la publicación de información audiovisual de carácter personal en Internet. La población juvenil se distribuye en tres segmentos de similar tamaño entre los que nunca publican sus fotografías y vídeos personales en Internet $(28,8 \%)$, los que lo hacen en raras ocasiones $(34,6 \%)$ y los que hacen con frecuencia $(36,6 \%)$. Los jóvenes mantienen posiciones divergentes respecto a la privacidad de su imagen personal: desde la reserva y opacidad hasta la vida privada expuesta en el ámbito público. Esta exposición está más extendida entre las mujeres que duplican la realización de estos comportamientos respecto a los 
varones ya que, casi la mitad, declara subir fotos y videos personales $(48,5 \%)$. Las motivaciones para publicar fotografías personales son diversas, desde el coqueteo y las relaciones hasta la difusión de momentos especiales entre el círculo cercano. El destino de las fotografías siempre es público y la mayoría de los espectadores de la imagen se presentan como desconocidos/ as. El individuo deja fragmentos de su biografía en la red, libremente expuestos a la mirada ajena. En el trasfondo, late un afán de notoriedad y autoperpetuación de individuos que convierten parte de su mundo privado en público.

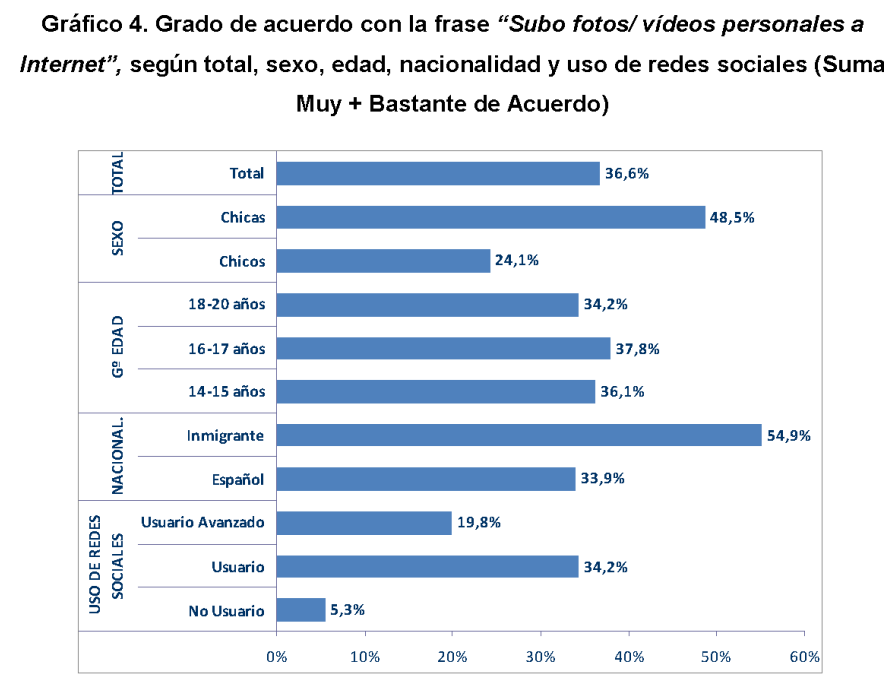

FUENTE: Elaboración propia.

Figura 5

La exposición de fotos y vídeos de los "otros cercanos" (amigos/as y familiares) es inferior en los datos generales pero supera el $40 \%$ en las mujeres que tienen mayor tendencia a difundir esta información. Se constata una comunión con los iguales con los que se comparten fiestas, eventos y momentos felices, con el vínculo afectivo (el cumpleaños de la abuela, el viaje de fin de curso, la salida con su grupo de amigos). La vida se presenta íntegra, sin censuras, ni recortes, reproduciendo el momento en el que fueron obtenidas. 


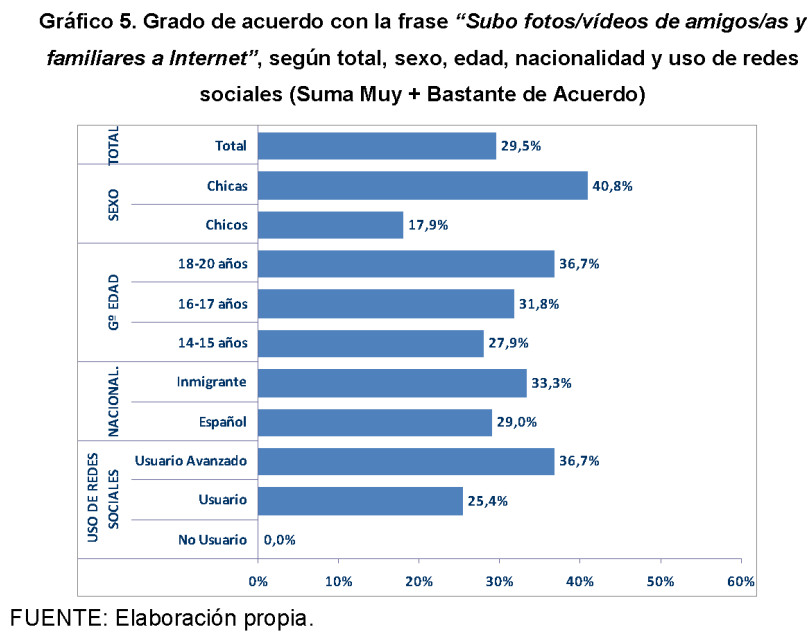

Figura 6

El individuo deja parte de sí mismo en la nube, con un rastro fotográfico y/o audiovisual de sí mismo y de sus seres queridos. Se hacen montajes, se suben fotos propias y de los/as amigos/as en sites webs, álbumes de las redes sociales, fotologs. La finalidad es la publicación para la exposición, la exhibición o el relato de la vida cotidiana, para extender esos momentos especiales y volver a revivirlos, compartiéndolos con los/as amigos/as,

Las chicas suben más fotos y vídeos personales, familiares y de amigos/as. Sin embargo, publican en menor proporción fotos en posturas sexys y no suelen mirar estas fotografías en Internet. El "pudor" (incluso, sólo mirar) es más frecuente entre la población femenina. Para los chicos, es una distracción frecuente, e incluso un $3 \%$ reconoce publicarlas.

No obstante, las mujeres siguen manifestando posiciones afectivas más abiertas en sus relaciones en Internet ya que agregan más personas desconocidas en su Messenger -ahora, en su Skype-. Casi el $9 \%$ declara hacerlo con frecuencia (frente al 5,2 \% de varones). El dato sigue la tendencia del Estudio sobre la seguridad y la e-confianza de los hogares españoles, realizado entre internautas mayores de 15 años (INTEC0, 2011: 30) en el que un 71,1\% manifestaba no agregar nunca desconocidos/as al Messenger.

ICONO14 | Año 2015 Volumen 13 Nº 1 | ISSN: 1697-8293 | DOI: ri14.v13i1.722 
No, sin mi móvil. Diferencias de género y uso de las nuevas tecnologías $\mid 232$

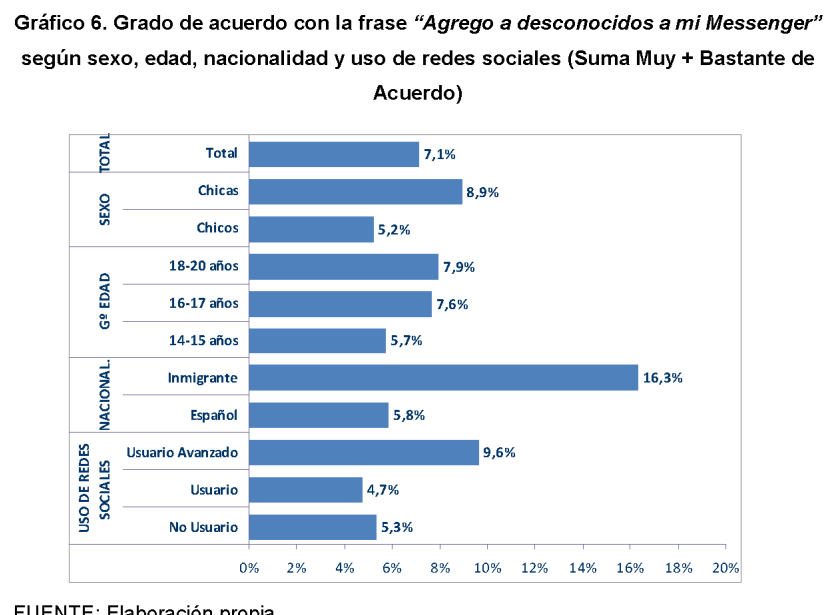

FUENTE: Elaboración propia.

Figura 7

Se agrega a desconocidos/as al Messenger para hablar con ellos/as. No obstante, el segmento que habla con desconocidos/as de temas personales constituye una minoría de las encuestadas $(6,4 \%)$. No hay diferencia estadísticamente significativa por sexo y edad pero los mayores de 18 años y las chicas suelen hacerlo con una frecuencia superior (sólo lo realiza el 5,6 \% de los varones). La mayor diferencia se presenta en relación con el uso de las redes sociales: los usuarios avanzados (que utilizan más de una red social) suelen relacionarse con desconocidos/as con una frecuencia superior.

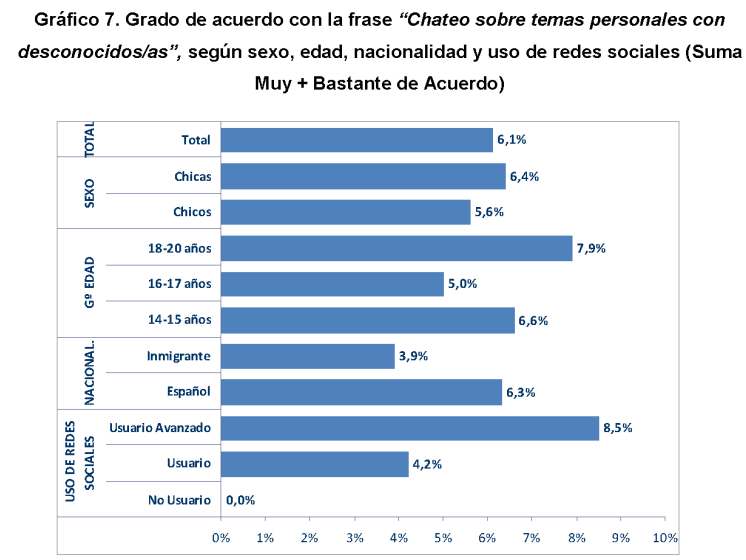

FUENTE: Elaboración propia.

Figura 8

DOI: ril4.v13i1.722 | ISSN: 1697-8293 | Año 2015 Volumen 13 Nº 1 | ICONO14 
La mayoría de usuarios/as no ha mantenido ningún tipo de contacto personal con desconocidos/as que ha conocido mediante el Chat (80,5\%). Así, mientras que un $11,0 \%$ ha quedado en alguna rara ocasión (casi nunca), un 4,5\% queda con frecuencia. El dato es similar a otra investigaciones, como los estudios Adolescentes y jóvenes en red: factores de oportunidad (Rubio, 2009: 41), un 77,2\% de jóvenes de 15-25 años no había quedado nunca con personas desconocidas y La Generación Interactiva, un 21\% de niños y adolescentes de 6-18 años reconocía haber quedado en alguna ocasión con amigos/as virtuales (Foro Generaciones Interactivas- Fundación Telefónica, 2009: 19). Entre el segmento que ha pasado de la interacción virtual a la relación personal, hay mayor presencia femenina, de mayores de edad y, sobre todo, de inmigrantes que se presentan como un colectivo más abierto en Internet.

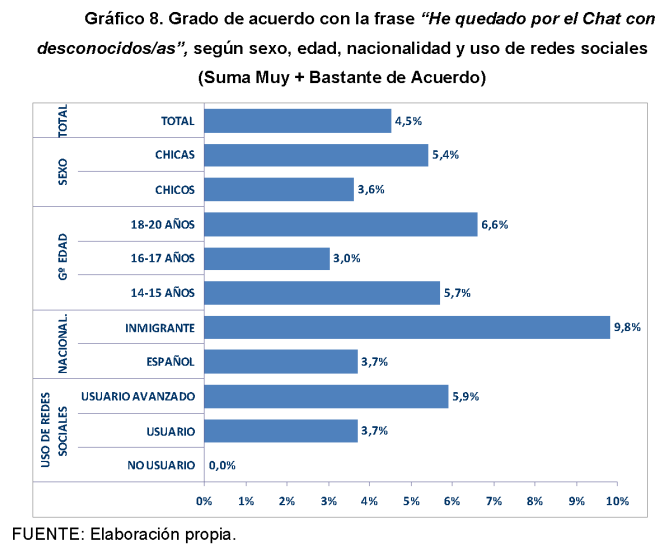

Figura 9

Las relaciones con personas desconocidas pueden implicar riesgos como la recepción de mensajes obscenos que indican que algunos jóvenes se arriesgan y posibilitan una forma de contacto directo (dirección de correo electrónico, móvil, redes sociales, etc.). Un 5,3\% reconoce haber sufrido esta situación, en especial las chicas que duplican a los chicos (6,9\% frente al 3,6\%). Se produce de forma más frecuente entre las chicas inmigrantes y las usuarias avanzadas de redes sociales. Se constata que son personas que asumen mayores riesgos por su mayor tendencia a relacionarse con desconocidos. 


\subsection{La presencia de las mujeres en las redes sociales}

Si la pertenencia a redes sociales es prácticamente universal (95\%), su uso aún se extiende aún más entre las chicas. De esta forma, sólo un 2,9 \% declara no utilizar redes sociales frente al 7,2\% de los varones.

\begin{tabular}{|c|c|c|c|c|c|c|c|}
\hline \multirow{2}{*}{ Respuestas } & \multicolumn{2}{|c|}{$14-15$ años } & \multicolumn{2}{|c|}{$16-17$ años } & \multicolumn{2}{|c|}{$18-20$ años } & \multirow{2}{*}{ TOTAL } \\
\cline { 2 - 7 } & Chicos & Chicas & Chicos & Chicas & Chicos & Chicas & \\
\hline Ninguna & 6,8 & 3,2 & 7,4 & 1,9 & 7,1 & 5,9 & 5,0 \\
\hline Sólo una red & 61,0 & 44,4 & 60,6 & 39,8 & 33,3 & 41,2 & 48,0 \\
\hline 2 redes sociales & 20,3 & 44,4 & 20,2 & 44,4 & 35,7 & 38,2 & 33,8 \\
\hline $\begin{array}{c}\text { 3 o más redes } \\
\text { sociales }\end{array}$ & 11,9 & 7,9 & 11,7 & 13,9 & 23,8 & 14,7 & 13,3 \\
\hline TOTAL & 100 & 100 & 100 & 100 & 100 & 100 & 100 \\
\hline
\end{tabular}

Tabla 6: Número de redes utilizadas ("Tengo cuenta y utilizo") por sexo y edad (\%). Fuente: elaboración propia.

Las chicas presentan también una penetración más extensiva (con un uso prácticamente generalizado) y más intensiva (con una frecuencia de uso semanal y diaria). El perfil multiusuario de redes sociales se caracteriza por la mayor presencia femenina (casi la mitad de chicas son usuarias de 2 redes sociales) y de jóvenes mayores de 17 años.

Las chicas utilizan más todas las funcionalidades de las redes sociales, fundamentalmente todas las que presentan un contenido más social, como el Chat, los mensajes privados, mirar otros perfiles, actualizar el perfil, escribir mensajes en el muro o tablón, invitar y contestar invitaciones, buscar amigos, y publicar y descargar contenidos. Las redes favorecen un modelo de proyección desde lo privado a lo público, al crear una sensación de colectividad común, de confianza con los más cercanos. Si bien, se constata que el individuo se siente más cómodo en las aplicaciones orientadas a la comunicación privada, las mujeres representan el pa- 
radigma del uso público ya que suelen publicar información con mayor frecuencia en todas las funcionalidades.

\begin{tabular}{|c|c|c|c|c|c|c|c|}
\hline \multirow{2}{*}{ Respuestas } & \multicolumn{2}{|c|}{ 14-15 años } & \multicolumn{2}{|c|}{ 16-17 años } & \multicolumn{2}{|c|}{$18-20$ años } & \multirow{2}{*}{ TOTAL } \\
\hline & Chicos & Chicas & Chicos & Chicas & Chicos & Chicas & \\
\hline Hablar por el Chat & 4,4 & 4,7 & 4,5 & 4,5 & 4,3 & 4,5 & 4,5 \\
\hline $\begin{array}{c}\text { Enviar mensajes } \\
\text { privados }\end{array}$ & 4,0 & 4,4 & 3,9 & 4,5 & 4,1 & 4,4 & 4,2 \\
\hline Mirar otros perfiles & 4,0 & 4,4 & 3,9 & 4,4 & 3,6 & 4,2 & 4,1 \\
\hline Actualizar mi perfil & 3,7 & 4,2 & 3,4 & 4,0 & 3,4 & 3,7 & 3,8 \\
\hline $\begin{array}{l}\text { Escribir mensajes } \\
\text { en el tablón }\end{array}$ & 3,5 & 3,9 & 3,2 & 3,9 & 3,5 & 3,9 & 3,7 \\
\hline $\begin{array}{c}\text { Invitar/responder } \\
\text { invitaciones de } \\
\text { nuevos/as amigos/ } \\
\text { as } \\
\end{array}$ & 3,4 & 3,7 & 3,2 & 3,4 & 2,8 & 3,0 & 3,3 \\
\hline $\begin{array}{l}\text { Públicar fotos/ví- } \\
\text { deos personales en } \\
\text { el tablón }\end{array}$ & 3,0 & 3,6 & 3,0 & 3,6 & 2,9 & 3,6 & 3,3 \\
\hline $\begin{array}{l}\text { Públicar vídeos y } \\
\text { enlaces públicos } \\
\text { en el tablón }\end{array}$ & 3,0 & 3,3 & 3,4 & 3,5 & 3,0 & 3,4 & 3,3 \\
\hline Buscar amigos/as & 3,4 & 3,6 & 3,2 & 3,1 & 3,0 & 3,1 & 3,2 \\
\hline $\begin{array}{c}\text { Descargar } \\
\text { imagenes/vídeos }\end{array}$ & 3,0 & 3,2 & 3,1 & 3,3 & 2,6 & 3,2 & 3,1 \\
\hline $\begin{array}{l}\text { Hacerme miembro } \\
\text { de grupo y/o fan } \\
\text { de páginas }\end{array}$ & 2,6 & 3,0 & 2,5 & 2,7 & 2,3 & 2,7 & 2,6 \\
\hline
\end{tabular}

Tabla 7: Uso de diferentes funciones de las redes sociales (medias), según edad y sexo. Fuente: elaboración propia.

Las chicas declaran tener más filtros en la admisión de contactos ya que sus redes tienen mayor número de amigos directos. Según su testimonio, tienen me- 
nos desconocidos/as y amigos de amigos. El contacto con personas desconocidas de otro género para la búsqueda de pareja es significativamente más alto entre los chicos de todas las edades. Sin embargo, el número de contactos de las chicas es superior. Se constata que las chicas son más intensivas en el uso de las redes sociales, lo que favorece una mayor interacción. No obstante, la selección cualitativa de los contactos no se corresponde con la apertura cuantitativa. Un 79,2\% declara limitar su red de contactos a su círculo social (amigos, compañeros, familiares y/o amigos de amigos). Sin embargo, el alto número de contactos (300-400) demuestra que, en la mayoría de casos, se amplía la relación a amigos/as virtuales que no son conocidos personalmente por el/la usuario/a.

\begin{tabular}{|c|c|c|c|c|c|c|c|}
\hline \multirow{2}{*}{ Respuestas } & \multicolumn{2}{|c|}{$14-15$ años } & \multicolumn{2}{c|}{$16-17$ años } & \multicolumn{2}{c|}{$18-20$ años } & \multirow{2}{*}{ TOTAL } \\
\cline { 2 - 7 } & Chicos & Chicas & Chicos & Chicas & Chicos & Chicas & \\
\hline $\begin{array}{c}\text { Número de } \\
\text { contactos }\end{array}$ & 290,1 & 354,4 & 289,9 & 327,0 & 307,3 & 263,3 & 310,1 \\
\hline
\end{tabular}

Tabla 8: Número medio de contactos de la red social, por edad y sexo. Fuente: elaboración propia.

\begin{tabular}{|c|c|c|c|c|c|c|c|}
\hline \multirow{2}{*}{ Respuestas } & \multicolumn{2}{|c|}{$14-15$ años } & \multicolumn{2}{|c|}{$16-17$ años } & \multicolumn{2}{c|}{$18-20$ años } & \multirow{2}{*}{ TOTAL } \\
\cline { 2 - 7 } & Chicos & Chicas & Chicos & Chicas & Chicos & Chicas & \\
\hline $\begin{array}{c}\text { Sólo amigos } \\
\text { personales }\end{array}$ & - & 4,9 & 1,1 & 2,8 & 5,1 & - & 2,3 \\
\hline $\begin{array}{c}\text { Amigos y } \\
\text { compañeros }\end{array}$ & 27,6 & 31,1 & 15,9 & 20,8 & 17,9 & 24,2 & 22,3 \\
\hline Familiares adultos & 24,1 & 39,3 & 36,4 & 43,4 & 23,1 & 48,5 & 36,6 \\
\hline Amigos de amigos & 41,4 & 32,8 & 43,2 & 41,6 & 46,2 & 36,4 & 40,6 \\
\hline $\begin{array}{c}\text { Desconocidos/as } \\
\text { (ligar) }\end{array}$ & 27,6 & 8,2 & 25,0 & 12,3 & 30,8 & 9,1 & 18,4 \\
\hline
\end{tabular}

Tabla 9: Tipo de relación con los contactos de la red social, según edad y sexo (\%). Fuente: elaboración propia. 


\subsection{Las mujeres y el móvil}

Las mujeres aparecen como las grandes "movilizadas" de la vida cotidiana. Incluso, desde que son menores de edad (entre 10 y 17 años), la extensión del móvil alcanza el 67,4\%. A partir de la mayoría de edad, prácticamente todas las chicas tienen, al menos un móvil, y su presencia es mayoritaria (llegando a alcanzar prácticamente el $100 \%$ de la población femenina) (INE, 2013).

Tanto en lo cuantitativo como cualitativo, la telefonía móvil constituye un objeto de estudio relevante en el análisis de los procesos de apropiación de la tecnología por parte de las mujeres y su inclusión en prácticas de gestión y construcción de la identidad de género. Las chicas presentan mayor proporción de uso de Internet con el teléfono móvil con una diferencia significativa de los chicos. También son las más intensivas en su uso, con mayor frecuencia de uso diario y semanal.

Gráfico 9. Uso de Internet en el teléfono móvil, según sexo y edad (\%)

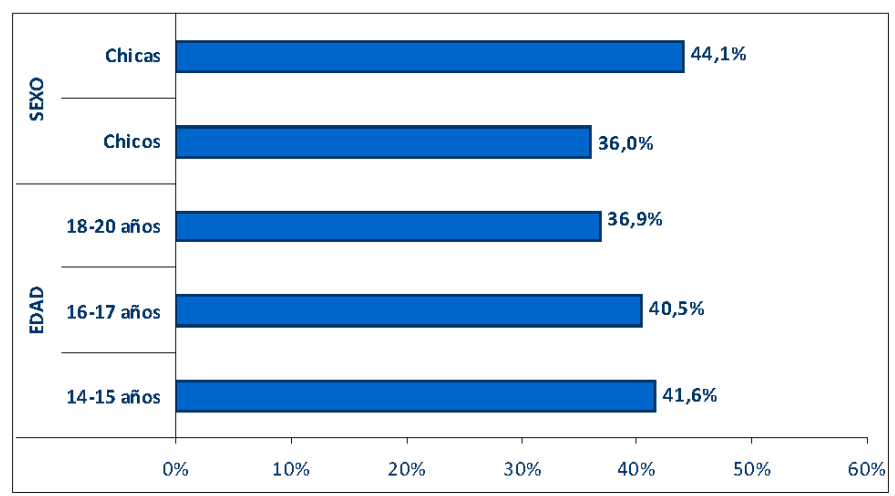

FUENTE: Elaboración propia.

Figura 10

Por género, las redes sociales en el móvil son un territorio predominantemente femenino, en especial entre las menores de edad. Sin embargo, en el segmento de 18-20 años, su importancia disminuye al ser desplazadas por el Whatsapp y la mensajería instantánea. Una herramienta comunicativa que si- 
gue teniendo un claro protagonismo en la cultura juvenil. Los chicos también las utilizan pero comparten su uso con la mensajería instantánea y se orientan también a otros contenidos, como los vídeos de youtube y las noticias de ocio y deporte. Respecto a otras aplicaciones, los varones más jóvenes ven más contenidos en Youtube, participan más en foros y leen más noticias de ocio y deporte.

\begin{tabular}{|c|c|c|c|c|c|c|c|}
\hline \multirow{2}{*}{ Respuestas } & \multicolumn{2}{|c|}{ 14-15 años } & \multicolumn{2}{|c|}{ 16-17 años } & \multicolumn{2}{|c|}{$18-20$ años } & \multirow{2}{*}{ TOTAL } \\
\hline & Chicos & Chicas & Chicos & Chicas & Chicos & Chicas & \\
\hline $\begin{array}{c}\text { Acceder a redes } \\
\text { sociales }\end{array}$ & 42,9 & 65,5 & 42,5 & 65,5 & 31,6 & 28,6 & 51,5 \\
\hline $\begin{array}{l}\text { Mensajería } \\
\text { Instantanéa }\end{array}$ & 23,8 & 17,2 & 22,5 & 20,0 & 47,7 & 50,0 & 25,8 \\
\hline Realizar consultas & 4,8 & 3,4 & 7,5 & 5,5 & 5,3 & 7,1 & 5,6 \\
\hline Correo Electrónico & 9,5 & 3,4 & 5,0 & 5,5 & 5,3 & 7,1 & 5,6 \\
\hline Youtube & 14,3 & - & 12,5 & 1,8 & - & - & 5,1 \\
\hline Foros & - & 6,9 & 2,5 & - & 5,3 & - & 2,2 \\
\hline $\begin{array}{c}\text { Noticias de ocio y } \\
\text { deporte }\end{array}$ & 4,8 & - & 5,0 & - & - & - & 1,7 \\
\hline Noticias generales & - & 3,4 & 2,5 & 1,8 & - & - & 1,7 \\
\hline Buscar direcciones & - & - & - & - & 5,3 & 7,1 & 1,1 \\
\hline TOTAL & 100 & 100 & 100 & 100 & 100 & 100 & 100 \\
\hline
\end{tabular}

Tabla 10: Primera aplicación de internet más utilizada en el teléfono móvil, según edad y sexo (\%). Fuente: elaboración propia.

Por género, el orden de relación se mantiene pero las chicas presentan una comunicación más intensiva y extensiva, se relacionan más y con más contactos, excepto con desconocidos. Sus relaciones con familiares adultos, en especial con sus padres y con otros familiares, son significativamente más altas. 


\begin{tabular}{|c|c|c|c|c|c|c|c|}
\hline \multirow{2}{*}{ Respuestas } & \multicolumn{2}{|c|}{ 14-15 años } & \multicolumn{2}{|c|}{ 16-17 años } & \multicolumn{2}{|c|}{$18-20$ años } & \multirow{2}{*}{ TOTAL } \\
\hline & Chicos & Chicas & Chicos & Chicas & Chicos & Chicas & \\
\hline Amigos/as & 89,5 & 95,2 & 91,2 & 95,3 & 92,9 & 94,1 & 93,1 \\
\hline Madre & 80,7 & 88,7 & 72,5 & 89,7 & 69,0 & 79,4 & 81,2 \\
\hline Padre & 66,7 & 74,6 & 62,6 & 71,4 & 66,7 & 70,6 & 68,6 \\
\hline $\begin{array}{c}\text { Familiares de tu } \\
\text { edad }\end{array}$ & 45,6 & 56,5 & 54,9 & 63,6 & 61,0 & 70,6 & 58,2 \\
\hline Novio/a & 48,2 & 43,1 & 59,6 & 60,0 & 62,5 & 64,7 & 56,2 \\
\hline $\begin{array}{c}\text { Conocidos/as } \\
\text { personales }\end{array}$ & 35,1 & 39,3 & 35,2 & 57,0 & 47,6 & 35,3 & 43,1 \\
\hline Familiares adultos & 17,5 & 35,5 & 28,6 & 46,7 & 32,5 & 32,4 & 33,8 \\
\hline $\begin{array}{c}\text { Conocidos/as } \\
\text { del chat }\end{array}$ & 7,0 & 6,5 & 10,0 & 8,4 & 2,4 & 0,0 & 6,9 \\
\hline Desconocidos/as & 0,0 & 0,0 & 3,3 & 0,0 & 7,3 & 2,9 & 1,8 \\
\hline
\end{tabular}

Tabla 11: Frecuencia de relaciones con el teléfono móvil, según edad y sexo (Suma Muchas + Bastantes veces) (\%). Fuente: elaboración propia.

\section{Conclusiones}

Para abordar estas conclusiones, seguimos los ejes semánticos de Martínez, Aguado y Tortajada (2009) definidas en el enfoque de la apropiación, entendida como el proceso de integración simbólica y funcional de la tecnología en la vida cotidiana y las transformaciones que ha posibilitado su uso.

1. La gestión de la identidad. Los estereotipos de género señalan un elemento de gestión de identidad, patente en las redes sociales y en las aplicaciones de comunicación. De esta forma, el uso de las redes sociales es superior en las chicas, sobre todo en el segmento de menor edad (14-15 años) que también aparece con mayor presencia en otras aplicaciones sociales, como el Chat, el correo electrónico, el Fotolog y el Skype. En esta línea, se presenta una dicotomía con aplicaciones masculinas que señalarían rasgos agente como la navegación por las páginas de Internet, la descarga de programas 
informáticos, la participación en los foros y el mayor uso de medio audiovisuales como la radio y la televisión. La división de géneros delimita una línea entre lo expresivo-comunal, un mundo más social y afectivo para ellas, y lo agéntico-instrumental, un mundo de acción, más audiovisual y utilitario para ellos.

Esta división del uso por género se constata también en otros estudios: “Ellas optan más por la virtualidad comunicativa de las pantallas: enviar y recibir mensajes, hablar, chatear...; ellos por el ocio y el entretenimiento: jugar, descargar películas o música... En definitiva, a la luz de estos resultados se plantea un escenario donde chicos y chicas buscan en las herramientas tecnológicas el modo de resolver sus particulares necesidades: ellas de relación, ellos de acción" (Foro de Generaciones Interactivas, 2009: 12).

Las chicas gestionan más sus roles públicos y privados a través de las nuevas tecnologías y se constata una mayor porosidad, en el sentido de una mayor penetración de uso del ordenador y del teléfono móvil en sus interacciones públicas. Mientras que, para los varones, hay una tendencia más breve en esta desconexión, referida a mensajes de contenido más pragmático (establecer citas, quedar para hacer recados) y en conversaciones de contenido generalmente más corto. Hay que constatar que la gestión de roles se produce de forma general y aumenta la tendencia a compatibilizar los escenarios públicos y privados de la vida cotidiana.

Si bien, las TIC se presentan como una forma de presentación en sociedad y como herramienta de socialización en ambos géneros, es más patente en las mujeres que las utilizan de forma más frecuente e intensiva.

2. La conciliación de la vida familiar/ afectiva y laboral, se relaciona más con la vida académica. Realmente, las chicas mantienen sus relaciones afectivas en las redes sociales; se encuentran más vinculadas a las agencias socializadoras formales, como la familia; por lo que su uso intensivo de Internet es predominantemente social. Pocas señales indican que utilicen este 
medio como un apoyo importante de sus trabajos de clase ya que su uso de la consulta de páginas web, el uso del correo electrónico y la descarga de programas son aplicaciones minoritarias para las chicas. Su universo es esencialmente emocional, como se transmite en el amplio uso de todas las funcionalidades de las redes sociales, en su uso intensivo del teléfono móvil con familiares y amigos/as y en el uso del chat que llegan a utilizar, incluso, para contactar con desconocidos.

El peso importante es la falta de segmentación entre lo público y lo privado. Si bien, las restricciones de los centros de enseñanza limitan estas relaciones; las jóvenes y adolescentes utilizan el espacio público académico o, incluso, su tiempo de tránsito en utilizar el Whatsapp o en otras aplicaciones sociales, como la visualización de vídeos o mensajes. Las jóvenes no sólo concilian sino que compatibilizan sus modos de vida sin esperar a acudir a ir a lugares privados para comunicarse con sus familiares, amigos/ as y conocidos/as.

Los varones sí que demuestran una mayor conciliación, no sólo escolar sino de otras actividades lúdicas. Utilizan más las páginas de descarga, los foros de consultas de programas y de juegos, la navegación por Internet, los vídeos de youtube y el correo electrónico, pese a que este uso sea netamente inferior al de las redes sociales y de aplicaciones como Whatsapp. La mujer, frente a ellos, es significativamente más afectiva y prosocial. Sin embargo, varones y mujeres comparten un predominante uso lúdico de las aplicaciones de internet ya que todas las funcionalidades vinculadas con las actividades académicas aparecen a una gran distancia de las redes sociales.

En este punto, tenemos que destacar la baja presencia de los mensajes de contenido social y altruista de las menores de edad. Los varones mayores de edad son más proclives a compartir estos contenidos a un nivel público mientras que las mujeres se decantan por su universo privado y por compartir su vida cotidiana con las personas más cercanas de su vida cotidiana. En esta línea, destaca la alta publicación de fotografías y de videos personales y de amigos y conocidos. Igualmente, sus relaciones con el ámbito educativo 
es minoritario, tanto en su pertenencia a redes con estos contenidos, como en sus relaciones con docentes o monitores.

La vida femenina no sólo es gráfica y audiovisual. Su vida también es el relato de su día a día. Un porcentaje significativo utiliza el chat para hablar de temas personales con conocidos y con desconocidos. En principio, parecen más prudentes por la restricción de contactos de conocidos en su red social -que suele ser Tuenti- pero los datos denotan que cuentan con un número medio muy superior de contactos en sus redes sociales. Nuevamente, las interacciones son predominantemente privadas pero comparten esta vida cotidiana en el tablón en mayor medida que los varones. Su uso incluye actividades privadas que comparten en el universo público de Internet.

3. El aspecto de seguridad ontológica se refiere, en este estudio, a la seguridad emocional. Este ámbito es, claramente, un elemento más asociado a las chicas que hace destacar sus relaciones telefónicas con las personas más cercanas, en especial, el alto uso con amigos de su edad y con sus familiares más cercanos (en especial, con su padre y con su madre). Las mujeres utilizan el refugio emocional de su círculo más íntimo para compartir las experiencias de su vida cotidiana, reducir su aislamiento en cualquier momento y lugar, y buscar la estabilidad de las personas más cercanas.

Un aspecto importante de seguridad emocional es el uso de Internet en lugares privados, una práctica más habitual en las mujeres que resguardan sus conversaciones de miradas indiscretas.

Sin embargo, sus efectos parecen contraproducentes con la seguridad física de una minoría y significativa parte de mujeres que declara recibir mensajes obscenos. Si bien es cierto que son mucho más prevenidas en la publicación de fotografías en posturas sexys, una actividad más relacionada con los varones; manifiestan actitudes más arriesgadas al quedar con desconocidos (6\%), en especial, las usuarias avanzadas de redes sociales. Su nivel de desconocimiento de los riesgos es alto pero, en la misma media, declaran controlarlos. 
Los varones son más instrumentales ya que utilizan en mayor medida la publicación de las fotos en posturas sugerentes para ligar con chicas de su edad. Utilizan más la imagen gráfica que el relato para establecer contacto con el otro sexo y reconocen más abiertamente incluir gente desconocida en sus redes sociales -pese a tener menor número de contactos-. Se denota diferencias entre los sexos en los riesgos de la exposición ya que una minoría de varones se declara más cómodo realizando este tipo de conductas, sin sufrir los problemas de recibir mensajes obscenos como es el caso de las mujeres.

La conclusión final es que, sin llegar a poder calificar los dispositivos como una apropiación exclusiva de cada género, las tendencias denotan significativas diferencias en las tendencias de uso: en el caso de las chicas, un uso más expresivo-comunal relacionado con las interacciones sociales, muy destacable en las relaciones sociales más cercanas, y compartido en las redes sociales a través de canales públicos, con contenidos más cargados de afectividad y mayor relato de sus experiencias cotidianas; mientras que los varones se orientan más a un uso agente-instrumental, más competitivo, más relacionado con la acción, en los juegos y en las aplicaciones TIC; con la novedad, con el uso compatible con otros medios de comunicación social y la información a través de foros de deportes y aplicaciones informáticas; y con tendencias más pragmáticas en sus contenidos (uso para quedar, para recados).

\section{Notas}

[1] En este trabajo, sólo se incluyen los datos con diferencias estadísticamente significativas entre los diferentes sexos. Se utilizan también otros indicadores demográficos como la edad, la etnia y el uso de las redes sociales para ampliar la interpretación de los resultados.

\section{Referencias}

Aguado, J. M.; Martínez, I. J. y Tortajada, I. (2009). Movilizad@s: mujery comunicaciones móviles en España. Feminismo/s 14, diciembre 2009, 15-34.

Aguado, J. M. y Martínez, I. J. (2007). The Construction of the Mobile Experience: The Role of Advertising Campaigns in the Appropriation of Mobile Phone 
Technologies. Continuum, Journal of Media and Cultural Studies. Vol. 21, 2 (2007), 137-148.

Bakan, D. (1966). The duality of human existence. Chicago: McNally.

Beaton, John y Wajcman, Judy (Eds) (2004) The Impact of the Mobile Telephony in Australia. Australian Mobile Telephony Conference. Sydney.

Beauvoir, S. de (1999). El segundo sexo. Buenos Aires: Sudamericana.

Butler, J. (2001). El género en disputa. El feminismo y la subversión de la identidad. México: Paidós.

Cuadrado, I. (2007). Psicología social y género en I. Cuadrado \& I. Fernández (Eds.), Psicología social (pp. 261-286). Madrid: Sanz y Torres.

Deaux, K. y Lewis, L.L. (1984). The estructure of gender estereotipes: Interrelationships amogn components and gender label. Journal of Personality and Social Psiochology, 46, 991- 1004.

Foro de Generaciones Interactivas y Fundación Telefónica (2009). La generación interactiva en España. Niños y adolescentes ante las pantallas. Disponible en: http://www.generacionesinteractivas.org/wp-content/uploads/2009/12/LaGeneración-Interactiva-en-España.pdf.

Gaviria, E. y López, M. (2013). Diferencias sexuales en los celos: el papel de la evolución y la identidad de género en López Sáez, M. et al. (2013) Cuaderno de investigación en Psicología Social (19-34). Madrid: Sanz y Torres.

Giddens, A. (1995). Modernidad e identidad del yo. El yo y la sociedad en la época contemporánea. Barcelona: Península.

Goffman, E. (1963). Interaction ritual: essays on face-to-face behavior. Nueva York: Anchor Books.

Grant, D. y Kiesler, S. (2001). Blurring the boundaries: cell phones, mobility and the line between work and personal life en Brown, B., Gree n, N. y Harper, R. (Eds). Wireless World. Social and Interactional Issues in Mobile Communication and Computing (121-132). Berlin: Springer-Verlag.

Instituto Nacional de Estadística (2014). Encuesta sobre equipamiento y uso de tecnologías de la información y comunicación en los hogares. Disponible en www.ine.es

Instituto Nacional de Nuevas Tecnologías (INTECO) (2011). Estudio sobre la seguridad de la información y la e-confianza de los hogares españoles. Tercer trimestre de 2010 (14a oleada). Colabora Plan Avanza2 y Ministerio de 
Industria, Turismo y Comercio. Enero, 2011. Disponible en http://www.inteco. es/Seguridad/Observatorio/Estudios_e_Informes/Estudios_e_Informes_1/ Estudio_hogares_3T2010

Islas Carmona, 0. (2008). El prosumidor. El actor comunicativo de la sociedad de la ubicuidad. Palabra Clave. Volumen 11 Número 1. Junio de 2008.

López Saéz, M. y Cuadrado Girado, I. (2013). en Gaviria, E.; López, M,.y Cuadrado,

I. Introducción a la Psicología Social (415-450). $2^{\text {a }}$ edición. Madrid: Sanz y Torres.

Lippmann, W. (1922). Public Opinion. Londres: Allen and Unwin.

Lemish, D. y Cohen, A. (2005). On the Gendered Nature of Mobile Phone Culture in Israel. Sex Roles, vol. 52, 7-8, 511-521.

Martínez, C. y Paterna, C. (2001). Autoatribuciones de género y su relación con los dominios familiar y laboral. Revista de psicología social, 16, 59- 70.

Money, J. (1988). Gay, straight, and in-between: The sexology of erotic orientation. New York: Oxford University Press

Monzón, A.S. (2004). La diversidad es riqueza: las relaciones de género en sociedades pluriculturales. Fundación Guatemala.

Moya, M. y De Lemus, S. (2004). Superando barreras: Creencias y aspectos motivacionales relacionados con el ascenso de las mujeres a puestos de poder. Revista de Psicología General y Aplicada, 57, (2), 225-242.

Papí Gálvez, N. (2001). Clase social, etnia y género: tres enfoques paradigmáticos convergentes. Red Científica. Ciencia, Tecnología y Pensamiento. Disponible en http://www.redcientifica.com/doc/doc200111100002.html

Parson, T. y Bales, R.F. (1955). Family, socialization and interation process. New York: Free Press.

Rubin, G. (1975). El tráfico de mujeres: Notas sobre la Economía Política del Sexo. Revista Nueva Antropología, Noviembre, Año/Vol. VIII, No 30.

Rubio Gil, M.A. (2009). Adolescentes y jóvenes en red: factores de oportunidad. Injuve. Disponible en http://www.injuve.es/contenidos.item.action?id=17247 74781\&menuId $=572069434$

Shils, E. (1966). Privacy: its constitution and vicissitudes. Law and Contemporary Problems Number 31. Pp. 281-305.

Smith, S. (2001). You Lose Your Mobile, You Lose Everything: An Exploratory Study of Mobile Phones, Sexuality, Gender and Space. Guilford, University of Surrey,

ICONO14 | Año 2015 Volumen $13 N^{\circ} 1$ | ISSN: 1697-8293 | DOI: ri14.v13i1.722 
United Kingdom.

Stoller, R. (1964). A Contribution to the Study of Gender Identity. International Journal of Psychoanalysis $n^{0} 45,220-226$.

Suler, J.R. (2002). Identity Management in Cyberspace. Journal of Applied Psychoanalytic Studies Number 4, 455-460.

Tafjel, H. (1984). Grupos humanos y categorías sociales. Barcelona: Herder.

Turkle, S. (1995). Life on the Screen: Identity in the Age of the Internet. Nueva York: Simmon and Schuster, 46-48.

Wajcman, J. (1991). Feminist Theories of Technology, en Janasoff , S.; Marle, G.; Petersen, J. y Pinch, T (Eds.). Handbook of Science and Technology Studies (189-204). Londres: Sage.

Westin, A. F. (1967). Privacy and freedom. New York: Atheneum.

Westin, A. F. (2004). Freebies and Privacy:What Net Users Think. 1999. Retrieved Aug 20, 2004.

Westin, A. F. (2004). Consumer, Privacy and Survey Research, 2003. Retrieved Aug 17, 2004.

Wittig, M. (1992). One is not born a woman. The straigth mind and other essays. Boston: Beacon Press. 